\title{
Preferred Futures—and How Do We Get There From Here?
}

The last several months have seen new attention being paid to alternative sources of energy, and to the area of energy efficiency in general. You can choose your own reason for taking an interest: reversing global warming, peak oil theory, escaping from OPEC's control of prices, stopping the flow of oil revenues to terrorist organizations, creating new jobs, or more parochially just generating more funding for research. These are all good reasons, and while some of them appeal to certain people more than others, there are now few people living in developed countries who deny the need to move away from dependence on oil, if not all fossil fuels.

Oil is used predominantly as an energy source for transportation, and the United States uses nearly as much of it per capita as any other nation on earth. Just for the record, the average Kuwaiti has a larger carbon footprint than the average American, but that is neither surprising nor especially significant. Canada and Australia are the closest major rivals to the United States in terms of carbon emissions per capita and it is easy to see why: both countries are geographically large, with highly mobile populations that rely primarily on cars and airplanes for getting around, just like the United States. Poorer countries that have fewer cars or planes, and smaller countries where travel distances are smaller, all have smaller carbon footprints per head of population than the United States, Canada, and Australia. Among these three, the United States has the biggest population and the greatest average carbon emissions per capita, and it has the biggest carbon footprint of any nation on earth.

President Obama is committed to dealing with these issues. He has hired a prominent greenhouse gas researcher, John Holdren, as the director of the White House Office of Science and Technology Policy, and a leader in the development of alternative fuels, Steven $\mathrm{Chu}$, as his Secretary of Energy. The chase is on, and materials researchers are eager to help in all of the many ways that we can.

The path forward is clear. Short-term gains can be realized by addressing efficiency issues, improving the average fuel consumption per mile traveled. In the longer term, the gains made by improving efficiency can be compounded by switching from petroleum to other portable fuels, whether it be to bio-derived liquid fuels, hydrogen, or electricity from batteries. There is almost unlimited potential for materials research to contribute in all of these areas.
Intriguingly, these efforts are being undertaken in the context of an economic recession that has had the effect of stopping people from buying cars, and encouraging increased use of public transportation. The U.S. government has provided bailout packages for the major U.S. automobile manufacturers, and is stimulating the economy by funding infrastructure projects that will sustain the roads that the cars drive on. This sounds very logical and reassuringly selfconsistent. After all, people will eventually start buying cars again, and we

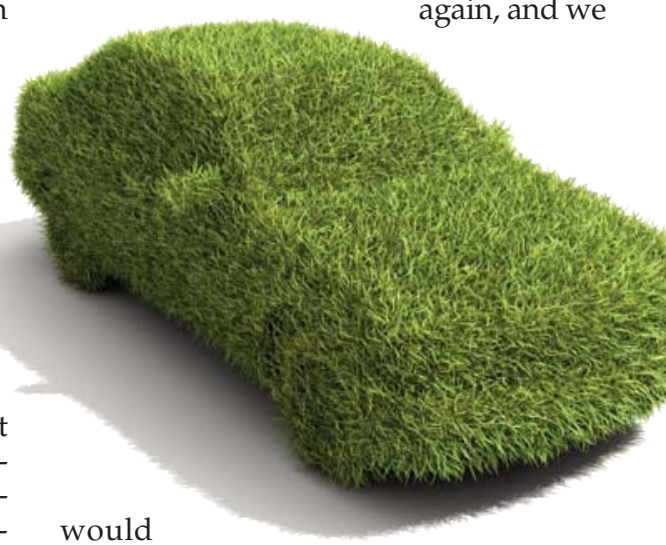

like them to

drive more eco-friendly vehicles on better roads.

The need to sustain the U.S. automotive industry is a very strong driver of the present strategy, but it is important to

We are now collectively embarking on a project of retrofitting an entire lifestyle, trying to maintain its look and feel, while reducing its environmental impact and using different fuels.

remember that Americans, Canadians, and Australians have cars and a carbased lifestyle as a result of choices that were made over 50 years of low-cost motoring. The "American Dream" consists largely of living in a large house in a pleasant suburban setting, and using the car to commute to work, to fetch the shopping, and to take the kids to their many activities, at least until they can drive there by themselves. Even my newspaper is delivered by car these days: no more the kid on a bicycle, as depicted in those old sit-coms.

If the economics of driving had been different for the baby-boom generation and its successors, then the whole landscape would have been different, indeed. Perhaps we would all live closer to where we work, and would use public transportation more often; we probably would not shop in malls surrounded by square miles of parking lots. Maybe the middleclass flight from the cities that characterized the 1960s and 1970s would have been different, too. But there is no use in considering what might have been. What is interesting to consider about the future, though, is the extent to which we should be working to find ways to sustain a lifestyle that was based on low-cost gasoline, and how much effort should be going into designing an infrastructure

that supports less driving overall? In

the short term, we simply must take care of the former; but in the longer term, maybe we will see some other shifts anyway.

Retrofitting anything involves some kinds of compromise, whether we are trying to modernize a building while maintaining its classical architecture, adapting a TV to access digital instead of analog broadcasts, or switching an existing car to run on a different fuel. We are now collectively embarking on a project of retrofitting an entire lifestyle, trying to maintain its look and feel, while reducing its environmental impact and using different fuels. There will be trade-offs, and economics will eventually affect peoples' choices about how they respond.

I wonder what our cities and towns will look like 50 years from now, as these economic forces take effect? I know that 50 years ago nobody imagined they would look like they do now. Maybe we can stretch our imagination to get a glimpse of that future, but maybe cannot get there from here-at least if we insist on going in a car. My own car does not get used much anymore, as I enjoy many benefits from living where I can walk to work. Driving 70\% less than the average American saves a lot more money and a lot more environmental impact than switching to any form of alternate fuel, and I suspect that others will want to make the same choice or opt for public transportation in increasing numbers as our automotive options change. Now, what new materials will be needed to support such a change in the lifestyle for the whole country?

ALEX KING 